La mortalidad en la población latina: algunas hipótesis

En comparación con la población blanca que no es de origen latino, la población latina en los Estados Unidos de América tiene menor escolaridad, mayores índices de pobreza y menos acceso a seguros de salud. Resulta paradójico, por consiguiente, que los latinos tengan tasas de mortalidad general y de mortalidad por enfermedades cardiovasculares y cáncer más bajas, aun después de hacer ajustes por el nivel de ingresos. ¿A qué se puede atribuir este fenómeno epidemiológico? Se han ofrecido explicaciones de dos géneros: primero, que la mortalidad más baja entre latinos es verdadera y que obedece a hábitos más sanos, una constitución genética más favorable y una mayor cohesión familiar; segundo, que el fenómeno no es verdadero, sino el resultado de la migración.

Los defensores de esta última postura argumentan que la mortalidad es menor en inmigrantes que en poblaciones que permanecen en su país de origen, y que los latinos recién llegados a Estados Unidos suelen tener mejor salud, según las estadísticas, que los que tienen más tiempo de haber abandonado su país. Pero un segundo argumento es el llamado "sesgo del salmón", según el cual el ser humano tiende a gravitar hacia su tierra natal cuando está próximo a morir y, como resultado, muchos latinos vuleven a su país cuando se jubilan o se enferman en la vejez. Debido a que las defunciones de estos emigrantes no quedan registradas en Estados Unidos, estas personas siguen figurando como si estuvieran vivas y hacen que la tasa de mortalidad en la población latina parezca más baja de lo que es en la realidad. Por último, hay quienes sostienen que la presión selectiva a favor de inmigrantes más sanos explica la paradoja.

Para poner a prueba la teoría del sesgo, cosa que no se ha hecho a satisfacción, un grupo de investigadores estadounidenses examinó los datos obtenidos en el Estudio Nacional Longitudinal de Mortalidad (National Longitudinal Mortality Study) para determinar las tasas de mortalidad entre cubanos, puertorriqueños y personas de origen latino que nacieron en Estados Unidos. Estas poblaciones son idóneas para un estudio de este tipo porque no están sujetas a los efectos del "sesgo del salmón" o del fenómeno del "inmigrante sano": los cubanos no pueden regresar a su país, los puertorriqueños figuran en los registros estadounidenses y los latinos que nacen en Estados Unidos no se ven afectados por los efectos de la inmigración.

Según los resultados, ni la hipótesis del "sesgo del salmón" ni la del "inmigrante sano" explica por qué los latinos tienen tasas de mortalidad más bajas que las personas blancas de distinta ascendencia. Por tanto, deben ser otros los factores responsables. Los autores reiteran la necesidad de efectuar investigaciones para determinar el posible efecto de factores culturales, en particular los hábitos relacionados con el riesgo de cáncer y de enfermedad coronaria. (Abraído-Lanza A, Dohrenwend BP, Ng-Mak DS, Blake Turner J. The Latino mortality paradox: A test of the "salmon bias" and healthy migrant hypotheses. Am J Public Health 1999;89(10):1543-1548).

\section{$¿$ Deben vacunarse contra la influenza las personas infectadas por el VIH?}

La vacuna contra la influenza se recomienda para pacientes infectados por el VIH, aunque no se han efectuado estudios para determinar su eficacia en este grupo. Los pacientes con infección por el VIH-1, particularmente los que tienen bajos los recuentos de linfocitos $\mathrm{CD} 4+$, suelen tener una respuesta muy débil a la vacuna contra la influenza. Esto ha llevado a algunos salubristas a insistir en que la vacunación de estas personas no es efectiva en función de su costo. Por añadidura, la vacuna se ha asociado con aumentos transitorios de la replicación del VIH y con pequeñas reducciones del porcentaje de células CD4+. No obstante, las implicaciones clínicas de estos dos fenómenos todavía no se han esclarecido.

Con el fin de estimar el posible beneficio de la vacunación anti-influenza de personas infectadas por el VIH, se llevó a cabo un estudio aleatorizado a doble ciego en una muestra de estos pacientes obtenida en la consulta externa de un hospital militar estadounidense. La eficacia, riesgos e inmunogenicidad de la vacuna se determinaron mediante una comparación con el grupo control, que recibió placebo. Se hicieron mediciones de anticuerpos antiinfluenza y de ARN de VIH-1 en plasma, así como recuentos de linfocitos CD4+ al ingreso en el estudio y uno y tres meses después de la vacunación. También se efectuaron cultivos víricos en los suje- 
tos que tenían síntomas respiratorios y se entrevistó a estos pacientes para obtener datos sobre su sintomatología.

De los sujetos que recibieron placebo, 23 (49\%) notificaron síntomas respiratorios, igual que 16 (29\%) de los que fueron vacunados $(P=0,04)$. En 10 de los controles y ninguno de los individuos vacunados se confirmó por pruebas de laboratorio la presencia de influenza sintomática $(P<0,001)$. La eficacia protectora de la vacuna se estimó en $100 \%$ (IC95\%: 73 a 100\%) y no se observó ningún efecto sobre las concentraciones plasmáticas de ARN del VIH-1 o los recuentos de células CD4+. De estos resultados se desprende que la vacuna anti-influenza muestra gran eficacia en personas infectadas por VIH-1 sin alterar de manera importante la carga vírica o los recuentos linfocitarios. (Tasker SA, Treanor JJ, Paxton WB, Wallace MR. Efficacy of influenza vaccination in $\mathrm{HIV}$-infected persons. Ann Intern Med 1999;131:430-433).

\section{Tendencias de la mortalidad materna asociada con eclampsia en México}

La eclampsia es una de las primeras causas de mortalidad materna en países en desarrollo y la más frecuente en mujeres mexicanas. Con objeto de definir el perfil clínico, sociodemográfico, perinatal y de laboratorio de mujeres en riesgo de morir por eclampsia, se realizó un estudio mediante la revisión de los expedientes de casos de muerte materna por dicha causa de 1991 a 1995 en un hospital del Instituto Mexicano del Seguro Social. Se determinó una frecuencia de muerte por eclampsia de 52,1\% (37 casos). Las pacientes tuvieron una edad promedio de 26 años, 54\% tenían dos o más embarazos - en la mayor parte de los estudios la frecuencia es más alta en primigestas - y $20 \%$ tenían hipertensión crónica como problema subyacente. La eclampsia se presentó a las 33 semanas de gestación, en promedio, siendo los síntomas más frecuentes la cefalea, los vómitos y las convulsiones, acompañados en ocasiones de dolor epigástrico y de signos de hiperreflexia. En concordancia con lo hallado por otros autores, $16 \%$ de las pacientes no tenían proteinuria (un valor $\geq 3 \mathrm{~g} / \mathrm{L}$ se observó solo en $45 \%$ de los casos) y $29,7 \%$ no tenían edema, lo cual indica que estas pacientes no presentaban el síndrome completo de preeclampsia.

Se observó al ingreso una tensión arterial sistólica promedio de $160 \mathrm{mmHg}$ y una diastólica de $110 \mathrm{mmHg}$. Las pruebas de laboratorio revelaron $<100000$ plaquetas por $\mathrm{mm}^{3}$, a veces con hemólisis, y un notable aumento de las transaminasas glutámico-oxalacética y glutámico-pirúvica como signo de lesión hepática. Este conjunto de hallazgos en una paciente da lugar al diagnóstico de HELLP (hemolysis, elevated liver enzymes, and low platelet count).

En conclusión, la paciente mexicana que fallece de eclampsia suele tener mayor edad y paridad que la típica embarazada y presentar enfermedad subyacente en etapa temprana del embarazo, con manifestaciones graves de carácter neurológico (convulsiones), hematológico (plaquetopenia y hemólisis) y hepático (elevación de las transaminasas) principalmente. Este perfil es útil para identificar a las pacientes en mayor riesgo de morir de preeclampsia y aplicar medidas preventivas oportunamente. (Lara González AL, García Alonso A, Macías Gallardo E, Alpuche G. Mortalidad materna por eclampsia: cinco años de revisión. Ginec Obstet Mex 1999;67:253-257).

\section{La carga de enfermedad en poblaciones pobres}

Según los cálculos mundiales y regionales, las enfermedades no transmisibles en personas de edad avanzada están cobrando mayor importancia en relación con otras causas de enfermedad a medida que la población envejece y que se aminoran las enfermedades transmisibles en neonatos y niños pequeños. No obstante, se trata de estimaciones generales que abarcan todos los estratos socioeconómicos y por lo tanto no reflejan la situación particular de las poblaciones más pobres en los distintos países. En un reciente estudio se calculó la carga de enfermedad del $20 \%$ de la población mundial que vive en los países con el menor ingreso per cápita y se establecieron comparaciones con el $20 \%$ que habita en los países más prósperos.

Se estimaron las defunciones y los años de vida ajustados por discapacidad (disability-adjusted life years, DALY) aplicando un procedimiento usado recientemente para calcular la carga de enfermedad en el mundo. Se hicieron proyecciones de la mortalidad en el año 2020 para el $20 \%$ más rico y más pobre de la humanidad, para lo cual se hicieron ciertas suposiciones sobre el futuro aumento o descenso de las enfermedades transmisibles y no transmisibles.

En 1990, las enfermedades transmisibles fueron las responsables de $59 \%$ de la mortalidad y discapacidad en el $20 \%$ más pobre de la población mundial, mientras que en el $20 \%$ más rico, las enfermedades no transmisibles causaron $85 \%$ de las defunciones y discapacidad. Si aumentara el valor de base del descenso de las enfermedades transmisibles entre 1990 y 2020, la esperanza de vida en las poblaciones más pobres aumentaría 10 veces más que en las más avanzadas (4,1 frente a 0,4 años). Sin embargo, el $20 \%$ más pobre de la población mun- 
dial obtendría solamente de una cuarta a una tercera parte del beneficio obtenido por el $20 \%$ más próspero de darse un aumento similar de las enfermedades no transmisibles ( 1,4 frente a 5,3 años). Como resultado, un descenso más acelerado de las enfermedades transmisibles cerraría la brecha entre ricos y pobres para el año 2020, pero si se produjera un descenso general más acelerado de las enfermedades no transmisibles, esta brecha se agrandaría.

Una limitación de este tipo de cálculos es que se basa en distintas suposiciones explícitas e implícitas. Una de ellas es que la relación costo-efectividad de las medidas reductoras de la mortalidad es la misma en todas las categorías de morbilidad y todos los grupos de población, independientemente del sexo, la edad y otras características. Los datos disponibles indican que las medidas destinadas a combatir las enfermedades transmisibles suelen ser más efectivas en función de su costo que las destinadas a controlar las enfermedades no transmisibles. De ser el caso, los resultados de este estudio subestiman el efecto potencial de las intervenciones contra las enfermedades transmisibles frente a las no transmisibles. Por añadidura, cabe recordar que en cada país las autoridades de salud nacionales pueden y suelen dirigir las iniciativas para el control de enfermedades a grupos de población específicos, como el de las personas más necesitadas, de manera que no siempre debe darse por sentado que las intervenciones surtirán el mismo efecto en todos los grupos. Aunque las estimaciones efectuadas en este estudio son inexactas, superan a otras proyecciones de la carga de enfermedad en las poblaciones pobres del mundo y a otras determinaciones del efecto que tendrán en estas poblaciones las medidas epidemiológicas contempladas para revertir las tendencias observadas.

Estos datos apuntan a la necesidad de tener precaución a la hora de desplazar la atención de las enfermedades transmisibles de la juventud a las no transmisibles que afectan principalmente a las personas de edad avanzada. Aunque este cambio de enfoque de las políticas de salud pública es justificable si se tiene presente el panorama mundial en su totalidad, las cifras reveladas en este estudio demuestran que este cambio equivale a restar importancia a las enfermedades que afectan eminentemente a las poblaciones pobres para dar mayor importancia a las que afectan a las poblaciones ricas. (Gwatkin DR, Guillot M, Heuveline P. The burden of disease among the global poor. Lancet 1999;354 (9178):586-589).

\section{Eficacia de la azitromicina en la prevención} de la neumonía por Pneumocystis carinii

En los países desarrollados, la neumonía por Pneumocystis carinii (NPC) sigue siendo la principal infección oportunista potencialmente mortal en pacientes infectados por el virus de la inmunodeficiencia humana (VIH). Aunque existen varios regímenes profilácticos, la intolerancia es frecuente (9-50\%). En estudios anteriores, la azitromicina, sola o combinada con rifabutina, fue superior a esta última en la prevención de la enfermedad diseminada por Mycobacterium avium. En modelos animales también se ha comprobado la superioridad de la combinación de azitromicina y sulfametoxazol frente a cualquiera de los dos fármacos por separado como profilaxis de la NPC.

En este estudio, basado en un ensayo clínico aleatorio a doble ciego cuyo objetivo primario consistió en determinar la eficacia relativa de la azitromicina, la rifabutina y la combinación de ambas en la prevención de la infección diseminada por $M$. avium, se presentan los resultados de un análisis de la eficacia de los tres regímenes en la prevención de la NPC.

Los criterios de inclusión fueron: edad superior a 17 años, seropositividad para el VIH-1, recuento de células CD4 $<100 / \mu \mathrm{L}$ en el año anterior, esperanza de vida de al menos 6 meses y ausencia de infecciones oportunistas activas y de hipersensibilidad a los fármacos estudiados. Aleatoriamente, los pacientes fueron asignados a uno de los tres tratamientos siguientes, que se administraron a doble ciego: azitromicina (1 $200 \mathrm{mg} / \mathrm{semana})$, rifabutina (300 mg/día) o ambos fármacos. Además se permitieron otros regímenes profilácticos tradicionales frente a la NPC (cotrimoxazol, dapsona, pentamidina u otros). Cada mes, los pacientes fueron sometidos a exámenes clínicos y de laboratorio. Asumiendo una tasa de NPC de $20 \%$ en el grupo tratado con rifabutina, la muestra de 724 pacientes proporcionó una potencia de $80 \%$ para detectar una disminución de $33 \%$ en la frecuencia de la NPC en los tratados con azitromicina, con un nivel de significación estadística de 0,05 . Los datos fueron analizados por intención de tratar. El riesgo acumulado de desarrollar un primer episodio de NPC se analizó con el método de Kaplan-Meier y las comparaciones se realizaron con la prueba de rango logarítmico (Cox-Mantel). En los análisis multivariados se utilizó el método de riesgos proporcionales de Cox. Se utilizaron pruebas bilaterales y se consideraron significativos los valores $P<0,05$.

De los 724 pacientes asignados a alguno de los tres tratamientos, 31 solo acudieron a la visita inicial, por lo que fueron excluidos del análisis; de los 693 casos restantes, 236 fueron tratados con rifabutina, 233 con azitromicina y 224 con el régimen combinado. El seguimiento (total de 932 pacientesaños) tuvo una duración mediana de 514 días.

En 78 pacientes se registraron 85 episodios de NPC, 48 de los cuales (56\%) correspondieron a in- 
fecciones primarias. En el grupo tratado con rifabutina se registró el doble de episodios de NPC por 100 años-paciente que en los grupos tratados con azitromicina o rifabutina y azitromicina. En los 44 casos (52\%) en los que el episodio de NPC fue diagnosticado por citología esta cifra fue cinco veces mayor en el grupo tratado con rifabutina que en el tratado con azitromicina. Globalmente, el riesgo de NPC fue $45 \%$ menor en los dos grupos que recibieron azitromicina que en el tratado únicamente con rifabutina.

La edad, la raza, el sexo, el recuento basal de células CD4 y los niveles de fosfatasa alcalina y hemoglobina no influyeron de forma significativa en la relación entre la profilaxis y la NPC. La única variable que afectó al desenlace fue la presencia de antecedentes de NPC en el examen basal. En un análisis exploratorio en el que los pacientes se agruparon en función de la presencia o ausencia de estos antecedentes, el efecto protector de los regímenes con azitromicina solo se manifestó en los 508 individuos sin antecedentes; en los 185 con antecedentes no se observó ningún beneficio.

Las menores tasas de NPC se registraron en los pacientes que también recibieron sulfonamidas. Entre los individuos (80\% del total) que recibieron cotrimoxazol o dapsona durante más de 30 días, la tasa de episodios confirmados de NPC fue de 4,5 por 100 años-paciente en el grupo tratado con azitromicina, frente a 8,5 en el tratado con rifabutina. De cualquier modo, la mayor reducción del riesgo se registró en los casos que tomaron sulfonamidas durante menos de 30 días; en este subgrupo, la tasa de NPC fue de 11,0 episodios por 100 pacientes-años en los casos tratados con azitromicina, frente a 60,9 en los tratados con rifabutina (razón de riesgo $=$ 0,23; intervalo de confianza de 95\%: 0,07 a 0,75).

Los efectos adversos fueron más frecuentes con el tratamiento combinado (90\%) que con la azitromicina $(88 \%)$ o la rifabutina $(76 \%)$. Lo mismo ocurrió con los efectos colaterales que obligaron a interrumpir el tratamiento: $23 \%$ con el régimen combinado, $14 \%$ con la azitromicina y $16 \%$ con la rifabutina.

Estos resultados revelan que, en pacientes sometidos a regímenes profilácticos tradicionales frente a la NPC, la profilaxis con dosis semanales de azitromicina frente a la infección por $M$. avium proporciona una significativa disminución adicional del riesgo de NPC. (Dunne MW, Bozzette $S$, McCutchan JA, Dubé MP, Sattler FR, Forthal D, Kemper CA, Havlir D, for the California Collaborative Treatment Group. Efficacy of azithromycin in prevention of Pneumocystis carinii pneumonia: a randomised trial. Lancet 1999;354: 891-895) 